03

\title{
Генерация направленных потоков микрочастиц путем сжигания газообразного топлива в нестационарном режиме
}

\author{
(С) В.В. Голуб, А.Д. Киверин, Т.Д. Садохина, И.С. Яковенко \\ Объединенный институт высоких температур РАН, Москва, Россия
}

ฯE-mail: yakovenko.ivan@bk.ru

Поступило в Редакцию 13 июля 2018 г.

Предложен подход к использованию процесса ускоренного распространения пламени в канале для генерации направленных потоков микрочастиц с целью их эффективного напыления на поверхность подложки в импульсном режиме. С помощью методов математического моделирования показана принципиальная возможность практического использования такого подхода и представлены количественные оценки эффективности предлагаемой методики при использовании газообразных смесей на основе водорода.

DOI: $10.21883 /$ PJTF.2018.22.46926.17463

Технология газотермического напыления микрочастиц на поверхность твердотельных подложек широко используется во многих отраслях промышленности для создания износостойких, антикоррозионных и термобарьерных покрытий. Методы газотермического напыления отличаются большим разнообразием подходов к созданию направленного потока микрочастиц, взаимодействующих с подложкой. Помимо ставших уже классическими методов газопламенного напыления и плазменного напыления интенсивно развиваются также технологии детонационного и высокоскоростного газопламенного напыления. Одним из последних был предложен метод холодного газодинамического напыления, интенсивно исследуемый в настоящее время [1]. Различные методы газотермического напыления обладают индивидуальным набором преимуществ и недостатков, что обусловливает различия в области их применения [2,3]. Актуальной задачей термического напыления сегодня является разработка эффективной технологии напыления наночастиц, 
что позволит создавать покрытия с принципиально улучшенными механическими, химическими и электрическими свойствами [4].

Среди методов создания направленных потоков микрочастиц с их последующим нанесением на подложку следует выделить использование реагирующего потока, что в дополнение к управлению динамическими характеристиками частиц позволяет также варьировать их термодинамические характеристики за счет изменения состояния несущего газа в ходе химических превращений. Из этого класса методик можно выделить два основных направления: напыление частиц в непрерывном режиме в факеле стационарного пламени и напыление в импульсном режиме в потоке за детонационной волной [5]. К достоинствам детонационного напыления можно отнести относительную технологическую простоту и надежность, широкий диапазон материалов покрытий, высокую адгезию и плотность покрытий, которые достигаются за счет ускорения частиц до высоких скоростей в потоке продуктов горения за детонационной волной [6]. При этом следует отметить основной недостаток такой методики, заключающийся в том, что существенную роль в динамике частиц играет отраженная от мишени ударная волна, что затрудняет эффективное напыление частиц малой массы. Ранее в [7] авторами предложена концепция профилирования подложки для повышения эффективности детонационного напыления микрочастиц. Говоря о детонационной имплантации частиц, важно понимать все особенности развития детонации в канале до и после взаимодействия с микрочастицами. Существует два основных механизма формирования детонации в канале: прямое инициирование и переход медленного горения в детонацию. При этом в последнем случае стадии формирования стационарной детонационной волны предшествует стадия ускорения пламени, характеризуемая вполне определенными пространственно-временны́ми масштабами. В канале, заполненном детонационно-способной смесью, формирование детонационной волны происходит на вполне определенном расстоянии от точки воспламенения, определяемом как параметрами смеси, так и геометрией канала. Здесь следует также отметить, что на преддетонационной стадии имеет место определенная последовательность развития потока газа перед фронтом ускоряющегося пламени. Под действием последовательности волн сжатия, формируемых в результате расширения продуктов горения в ограниченном объеме канала за фронтом ускоряющегося пламени, газ сжимается и ускоряется. Учитывая низкую эффективность исполь-

Письма в ЖТФ, 2018, том 44, вып. 22 
зования детонационного напыления микрочастиц из-за влияния сильных первичной и отраженной ударных волн [7], целесообразно использовать поток, формируемый на нестационарной стадии ускорения пламени в канале до образования детонационной волны. С одной стороны, в таком потоке отсутствуют сильные ударные волны, отражение которых от поверхности подложки существенно тормозит поток газа с частицами. С другой стороны, непрерывно ускоряющийся поток должен способствовать постепенному ускорению частиц в направлении подложки, что также должно обеспечивать направленное движение частиц на фоне развернутого о поверхность подложки потока. В связи с этим основной целью настоящей работы является проведение анализа эффективности режима напыления микрочастиц в импульсе, сформированном в ходе ускорения пламени в канале. Для достижения поставленной цели методами численного моделирования была решена задача о напылении слоя микрочастиц при сгорании водородно-кислородной и водородновоздушной смесей в трубке круглого сечения.

Опишем более подробно постановку задачи численного моделирования. Будем рассматривать направленное движение микрочастиц из трубки диаметром $1.0 \mathrm{~cm}$ в направлении плоской мишени, расположенной параллельно срезу сопла на расстоянии $2.0 \mathrm{~cm}$ от него. В начальный момент времени трубка целиком заполнена предварительно перемешанной горючей смесью при нормальных условиях, окружающая среда в зазоре между срезом сопла и мишенью - воздух при нормальных условиях. Слой частиц толщиной $0.1 \mathrm{~cm}$ располагается непосредственно на срезе сопла и в поперечном сечении занимает все сопло. Инициирование горения производится в тонком плоском слое нагретого до $3000.0 \mathrm{~K}$ газа вблизи закрытого торца трубки. Пламя распространяется от закрытого торца к открытому с ускорением, что определяет условия формирования потока газа, вовлекающего в движение микрочастицы в направлении мишени. В зависимости от протяженности трубки возможно несколько режимов. В случае выбора длинной трубки горение переходит в детонацию, и напыление частиц происходит в импульсе сформированной детонационной волны. В случае коротких трубок, меньших по длине по сравнению с дистанцией перехода к детонации, напыление происходит в потоке, генерируемом ускоряющимся пламенем. В связи с этим в ходе исследования длина трубки варьировалась, что позволило детально проанализировать эффективности различных режимов, в том числе провести их взаимное сравнение. Расчеты проводились для

Письма в ЖТФ, 2018, том 44, вып. 22 
двух смесей: стехиометрической водородно-кислородной и стехиометрической водородно-воздушной. В первом случае (для высокоактивной смеси) длина перехода к детонации мала, и рассмотренные режимы ограничены относительно малой протяженностью процесса. В случае менее активной водородно-воздушной смеси была возможность рассмотреть влияние времени процесса на его эффективность.

Задача решалась в континуальном приближении, в рамках которого динамика обеих фаз (несущего газа и дисперсной фазы взвешенных в газе частиц) описывалась уравнениями механики сплошной среды. При этом учитывался обмен импульсом и энергией между частицами и несущим потоком. Соответственно ускорение частицы приобретали в результате стоксовского взаимодействия с потоком газа. Расчеты проводились с использованием эйлерово-лагранжева метода, успешно используемого авторами ранее для решения широкого круга задач горения и детонации газообразных и дисперсных сред [8].

Как было продемонстрировано ранее [7], трудоемким представляется детонационное напыление частиц мельче $100 \mu \mathrm{m}$ (при плотности вещества $1.0 \mathrm{~g} / \mathrm{cm}^{3}$ ). Здесь будем рассматривать частицы диаметром $2.0 \mu \mathrm{m}$. В первую очередь рассмотрим напыление частиц при реализации нестационарного горения в трубке протяженностью $L=10.0 \mathrm{~cm}$. Согласно проведенным предварительно расчетам с применением кинетического механизма [9], переход горения в детонацию в трубке заданного диаметра, заполненной водородно-кислородной смесью, реализуется на расстоянии в $9.0 \mathrm{~cm}$ от закрытого торца. Таким образом, в случае выбора трубки протяженностью $10.0 \mathrm{~cm}$ имеет место режим ускорения частиц в импульсе детонационной волны. Столь мелкие частицы диаметром $2.0 \mu \mathrm{m}$ увлекаются потоком непосредственно за фронтом детонационной волны. После выхода из трубки в нереагирующую атмосферу волна детонации распадается на отошедшую ударную волну и контактный разрыв между воздухом и продуктами детонации. При этом микрочастицы продолжают двигаться в потоке расширяющихся продуктов детонации и, обладая малой инерцией, практически полностью повторяют дальнейшее течение газа. Отошедшая ударная волна отражается от поверхности подложки и вызывает торможение продуктов детонации после пересечения контактного разрыва. Это же приводит к торможению микрочастиц и смене направления их движения в пространстве, что препятствует их достижению поверхности подложки.

Письма в ЖТФ, 2018, том 44, вып. 22 

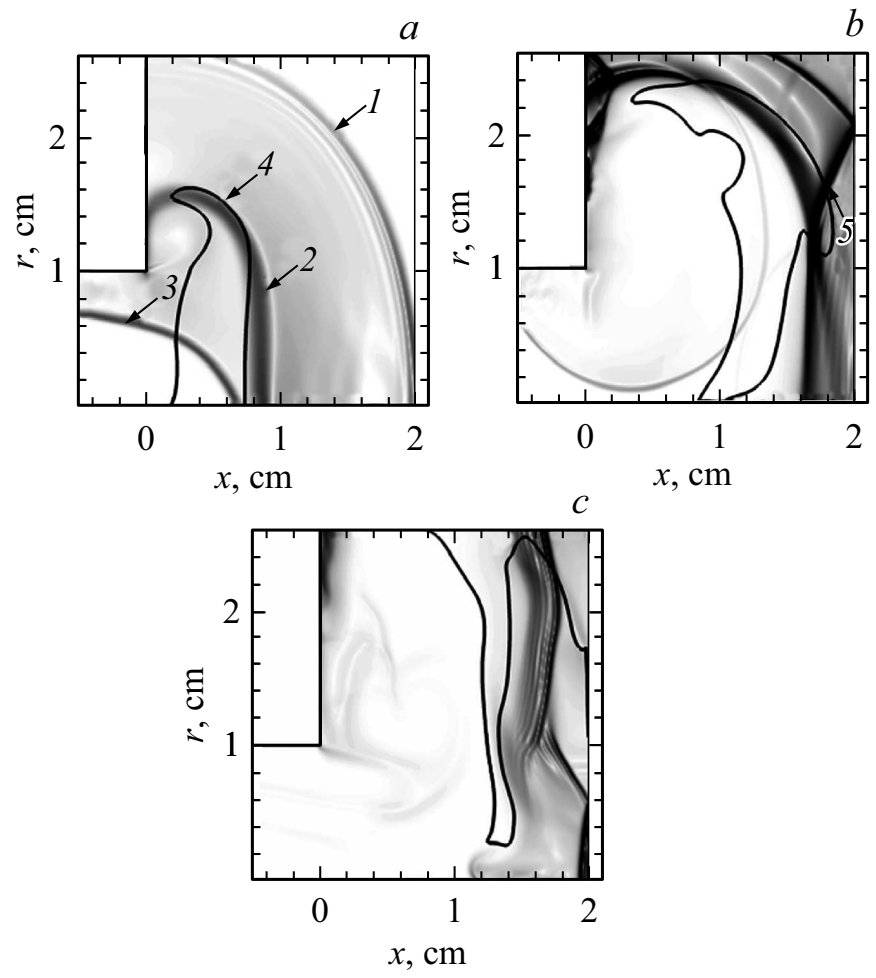

Рис. 1. Характерные поля течений формируемых при напылении частиц при ускорении пламени в трубке длиной $0.65 \mathrm{~m}$ через $160(a), 190(b)$ и $220 \mu \mathrm{s}(c)$ с момента воспламенения. 1 - первичная ударная волна, 2 - контактный разрыв между атмосферным воздухом и истекающей в него водородно-кислородной смесью, 3 - фронт пламени, 4 (сплошная линия) - граница облака частиц (на фрагменте $c$ видимая часть облака частиц располагается выше черной линии), 5 - отраженная ударная волна. Теневая гамма показывает поле нормированной величины градиента плотности. $x=0-$ срез сопла, $x=2-$ поверхность подложки.

В случае выбора короткой трубки процесс развивается несколько иным образом. Рассмотрим режим, реализующийся при использовании трубки протяженностью $4.5 \mathrm{~cm}$. В данном случае к моменту выхода

Письма в ЖТФ, 2018, том 44, вып. 22 
пламени из трубки перехода к детонации не наблюдается. При этом пламя ускоряется лишь до $60 \mathrm{~m} / \mathrm{s}$. Как уже отмечалось выше, ускорение пламени соответствует ускорению потока свежего газа перед фронтом пламени, вытесняемого из трубки расширяющимися продуктами горения. Микрочастицы увлекаются потоком вытесняемого газа в зазор между срезом сопла и поверхностью подложки. При этом непрерывное ускорение потока способствует все большему и большему ускорению микрочастиц, что позволяет им преодолеть противодавление со стороны отраженного от подложки течения. Это можно видеть из анализа структуры многофазного потока, представленной на рис. 1 . В рассматриваемом случае наблюдается достижение микрочастицами подложки, при этом из всех частиц на подложке оседает $1.4 \%$. На рис. 2, $a$ показана зависимость удельной доли частиц, осевших на поверхности подложки, в зависимости от протяженности трубки. Как можно видеть, режим с максимальной эффективностью напыления реализуется при выборе трубки некой промежуточной длины $(6.5 \mathrm{~cm})$. Таким образом, можно заключить, что предлагаемая концепция вполне правомерна и для частиц заданных размера и массы можно подобрать параметры системы (геометрия трубки и состав реагирующей смеси), обеспечивающие наиболее эффективное напыление микрочастиц на поверхность подложки. Здесь следует отметить, что для использованной высокоактивной смеси водорода с кислородом диапазон геометрических параметров весьма узок, что может препятствовать практическому применению предлагаемой концепции. С целью всестороннего анализа были проведены аналогичные расчеты с использованием менее химически активной водородно-воздушной смеси, анализ результатов которых представлен далее.

Переход горения в детонацию в водородно-воздушной смеси реализуется на существенно бо́льших пространственно-временны́х масштабах по сравнению со случаем водородно-кислородной смеси. Более того, часто для обеспечения перехода к детонации в водородно-воздушной смеси необходимо создавать дополнительные условия, такие как, например, турбулизация среды. Тем не менее пламя в канале, заполненном водородно-воздушной смесью, так же как и в предыдущем рассмотренном случае, ускоряется, и появляется возможность наблюдать развитие описанного выше процесса вовлечения микрочастиц в непрерывно ускоряющийся поток на больших пространственно-временны́х масштабах. Как показывают расчеты, это ведет к существенному расширению

Письма в ЖТФ, 2018, том 44, вып. 22 

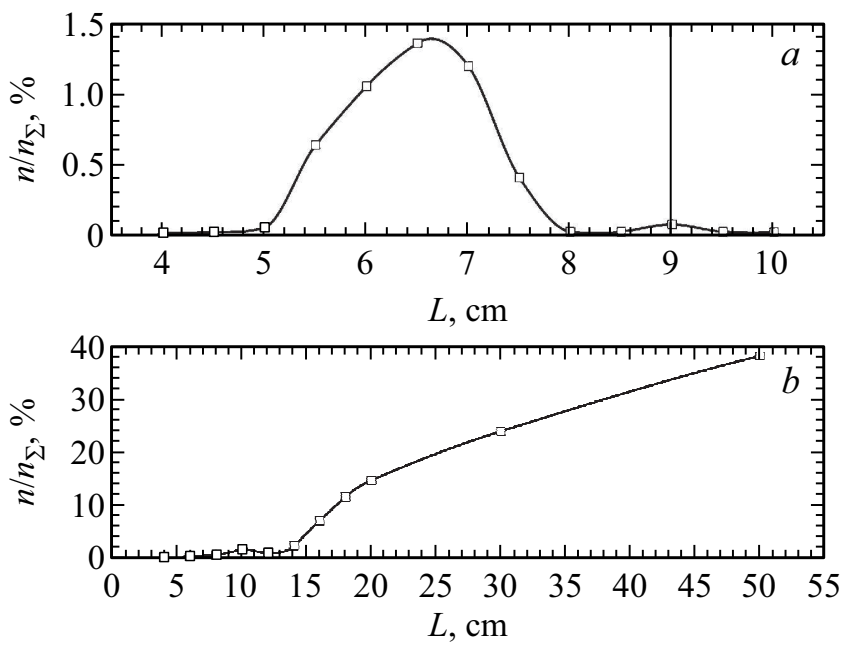

Рис. 2. Зависимость от протяженности трубки числа частиц, напыленных на твердотельную подложку при ускорении пламени в канале, заполненном стехиометрической водородно-кислородной $(a)$ и водородно-воздушной $(b)$ смесями. На части $a$ вертикальная линия показывает длину трубки, соответствующую переходу в детонацию.

геометрического диапазона и позволяет наблюдать режимы с большей эффективностью напыления частиц на подложку. Рис. $2, b$ демонстрирует аналогичную представленной на рис. $2, a$ зависимость для случая водородно-воздушной смеси. Можно видеть, что в рассмотренном диапазоне длин трубки имеет место непрерывное нарастание доли осевших на подложке частиц с увеличением протяженности разгонного участка. При этом становится возможным повышение эффективности напыления. Так, например, при использовании трубки длиной $50 \mathrm{~cm}$ эффективность имплантации повышается до $38.2 \%$. Здесь нужно отметить, что полученные количественные данные по определению удельной массы осевших на подложке частиц ввиду ограниченности выбора конкретных параметров постановки задачи следует трактовать исключительно как качественный результат, иллюстрирующий принципиальную работоспособность предлагаемой методики.

В заключение сформулируем основные результаты работы.

Письма в ЖТФ, 2018, том 44, вып. 22 
1. Предложена концепция импульсного напыления микрочастиц в потоке, формируемом при ускоренном распространении пламени в канале.

2. Принципиальная работоспособность предложенной методики продемонстрирована на примере использования водородно-кислородной и водородно-воздушной смесей, включая сравнение результатов с полученными по методике детонационного напыления микрочастиц.

Исследование выполнено за счет гранта РНФ 14-50-00124.

\section{Список литературы}

[1] Moridi A., Hassani-Gangaraj S.M., Guagliano M., Dao M. // Surf. Eng. 2014. V. 30. N 6. P. 369-395. DOI: 10.1179/1743294414Y.0000000270

[2] Fauchais P.L., Heberlein J.V.R., Boulos M.I. Thermal spray fundamentals: from powder to part. N.Y.: Springer, 2014. 1566 p. DOI: 10.1007/978-0-387-68991-3

[3] Saber-Samandari S., Berndt C.C. // Int. Heat Treatment Surf. Eng. 2010. V. 4. N 1. P. 7-3. DOI: $10.1179 / 174951410 X 12572442577381$

[4] Killinger A., Kuhn M., Gadow R. // Surf. Coat. Technol. 2006. V. 201. P. 1922 1929. DOI: $10.1016 /$ j.surfcoat.2006.04.034

[5] Pawlowski L. The science and engineering of thermal spray coatings. Chichester (UK): John Wiley \& Sons, Ltd, 2008. 626 p. DOI: 10.1002/9780470754085

[6] Kharlamov Y.A. // Mater. Sci. Eng. 1987. V. 93. P. 1-37. DOI: 10.1016/00255416(87)90409-5

[7] Голуб В.В., Иванов М.Ф., Киверин А.Д., Яковенко И.С. // Письма в ЖТФ. 2014. T. 40. B. 20. C. $88-95$.

[8] Efremov V.P., Ivanov M.F., Kiverin A.D., Yakovenko I.S. // Results Phys. 2015. V. 5. P. $290-296$. DOI: $10.1016 /$ j.rinp.2015.10.003

[9] Keromnes A., Metcalfe W.K., Heufer K.A., Donohoe N., Das A.K., Sung C.-J., Herzler J., Naumann C., Griebel P., Mathieu O., Krejci M.C, Petersen E.L., Pitz W.J., Curran H.J. // Combust. Flame. 2013. V. 160. P. 995-1011. DOI: $10.1016 /$ j.combustflame.2013.01.001 